\title{
SULPHUROUS MINERAL WATERS
}

Iliuta Alexandru,

\section{Institutul Naţional de Recuperare, Medicina Fizica şi Balneoclimatologie}

Sulphurous waters contain at least $1 \mathrm{mg}$ H2S, HS, S or thiosulphate per liter or complex colloidal sulfur water is presented as of simple or mixed sulphide (alkali, carbonated, chlorinated sodium).

In the sulphurous waters, sulfur is found in several forms (hydrogen sulfide, free sulfide, sulfide groups, polysulfides acids). Yellow, opalescent white precipitate and deposit a glass of water on the bottom of sulphur oxidation by indicates the intensity of the wateroxidation process by oxygen in the air.

In our country sulphurous waters have curative qualities. One of the most important sources of sulphur water is found in Dambovita County, namely Pucioasa. The village is famous among those with neurological and rheumatic diseases. Olt Valley, in Calimanesti, hat and sulphurous waters Cozia, are really wonderful, both in cure external and internal.

Other famous villages are Harghita Bai and Govora Bai, but also Barzava Bai, Baile Boghis (Salaj County), Olanesti and those on the seaside: Venus and Mangalia.

At Herculane, resort arranged and operated for the first time 2000 years ago; you have besides sulphurous water of a special quality, the possibility of making cures with thermal waters.

Due to high concentrations of sulfur, which gives them a bad taste, they cannot be used as table water, but only as medicinal waters.

Sulphurous waters have drinking indications and external cures indications in the form of baths, inhalations and vaginal irrigations, due to the effects of $\mathrm{H}_{2} \mathrm{~S}$, which passes through the skin and through stomach mucus membranes, the upper airway, the bronchopulmonary and vaginal membranes.

Sulpurous water drinking, usually mixed, has effects on stimulating gastric secretion (the bicarbonate tampon this effect) as the bowel movements, and Bile means chloretic effects on the liver and bile ducts, and antitoxic effects of lowering blood sugar in diabetics. The mixed sulphurous-carbonated waters have also diuretic effects by the action of $\mathrm{CO}_{2}$.

The indications for internal cure with sulphurous waters of low concentrations are: hepatobiliary disease, especially biliary dyskinesias, cholelithiasis and chronic cholecystitis, urinary infections, diabetes and forms of heavy metal poisoning.

Internal cures with sulphurous waters are practiced in Caciulata and Calimanesti resorts, Olanesti Bai, as in Herculane and Mangalia.

Sulphurous waters are able to cure many diseases, by the content of hydrogen sulphide, which is the only sulfur compound that is absorbed into the body through the skin, lung and digestive way, and eliminated through the skin, intestine and kidney.

These waters are indicated in constipation, colitis, hepatitis, diabetes and chronic poisoning with heavy metals (mercury, lead, zinc).

These waters have a stimulating effect on the secretory glands of the skin and bronchial mucous membranes. Are useful in treating liver diseases (hepatomegaly, dyspepsia), splenomegaly, digestive diseases, colic, ascites, some cases of chronic fever. Baths with sulphurous thermal water heal skin affections such as psoriasis, pityriasis, eczema, scabies, itching, acne.

Serious skin diseases can be cured by the use of ointments containing high concentrations of sulfur. The thermal baths are useful in cases of asthma, cough, rheumatism, gout chronic consumptive or debility.

Inhalations therapy with sulphurous water is indicated in respiratory and ORL for the effects of anti-inflammatory, antiseptic and desensitised the upper airway mucosa and tracheobronchial, with mucus. Inhalations and sprays are givenindividual or collective in patients with BPOC, asthma, sinusitis, allergic rhinitis, ozen.

An original method of administration is par enteral therapy with sulphurous water, by the injections of water and springs from Olanești, Calimanesti and Caciulata resort, indicated in the treatment of allergic skin, digestive or respiratory, possibly associated with external and internal cures with sulphurous water or therapy inhalations administered in individualized manner. 


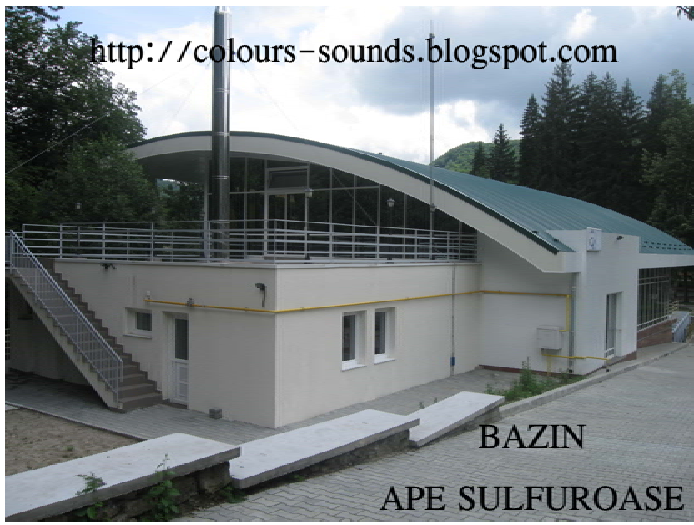

Figure 1. Olanesti sulphurous waters pool

\section{Internal administration of sulphurous water}

- Sulphurous waters have a bitter taste, astringent and a strong odor, sulfurous waters taken internally in small doses of 50-100 ml per day, have a laxative, diuretic and sudorific.

- When administered at higher doses (100$300 \mathrm{ml}$ ) can generate a laxative effect. Therefore are indicated in constipation, especially when it is associated with hemorrhoids.

The mechanisms by which sulphurous waters exerts beneficial effects on the bodyare:

- Heat activates the circulation to the tissue bath and help sick and excitement to their skin resorption, which produce antibodies to combat infectious status for certaint types of rheumatism. Sulfur assimilated by the body increases basal metabolism by $40 \%$, cause cutaneous vasodilation in the central network, bringing about lower blood pressure, are located in diseased joints, and even in the healthy red blood cells increases the number and amount of hemoglobin.

- Dynamic components including physical production is also mentioned increased sweating, decreased muscle excitability, speeding and causi ng resorption exudatessedative action explaining pain relief. Reabsorbed sulfur interferes in the body's general metabolism, which explains the decrease in blood glucose in diabetics, recovering sulfuric acid chondroitin articular cartilage of the rheumatics.

- vasodilatator effect skin: cutaneous peripheral blood flow increases, vascular resistance decreases and decreases peripheral diastolic pressure

metabolic effect: lowers blood sugar keratolytic effect: taking off surfaces covered by keratosis scales and favors elimination

- effects on articular cartilage: articular sulfur level reached and thus decreases ischemia induces vasodilation by activating defense capacity and functional integration structures.

\section{Musculoskeletal disorders}

These diseases included rheumatic, inflammatory, degenerative, abarticular, posttraumatic sequelae of the hands and feet, etc.

To recover of these diseases follow these objectives:

o combating pain and inflammation, preventing deformation and ankylosis;

o muscle tension combating, restoring muscle tone and strength;

0 recovery of joint mobility.

In the case of inflammatory rheumatism, prophylactically cure is indicated in allergic conditions as rheumatic fever or infection after the outbreak, the body reacts violently to any microbial aggression with joint pain.

Treatment with sulphurous waters for therapeutic purposes is indicated in poliarthritis, as in ankylosing spondylitis, evolving forms of central or peripheral arthritis.

In the degenerative rheumatism, cure prophylactically are recommended for preartrozic states to children, adolescents, youth with disorders of the locomotor system still in working conditions with peripheral circulatory disorders muscle application.

It is recommended also in cervical spondylosis, lumb or back (without blokining events) in osteoarthritis of the hip and poliarthritis light located on the hands and feet.

Peripheral neurological diseases

These disorders represent a large category of nerve damage whose frequency is increased due to increased number of injuries due to road accidents.

Cure for therapeutic purposes are recommended for the following conditions: mildparesis recently with favourable evolution and potentioal minor sequelae after polyneuropathies.

The recovering cure is indicated for: posttraumatic limb paralysis and parasites, 
polyneuropathies after the acute phase; ponytail syndrome, sequalae after poliomyelitis secondary with impaired tendon, in view of corrective surgery.

Through the recovering cure in the resort is obtained: avoid loss of mobility and muscle strength, prolonged immobilization or joint injuries, muscle, etc.; replay activity as innervation and development of compensatory functions in the segments affected sensitivity of progressive rehabilitation, removal of trophic disorders and vegetation, combating pain and inflammatory sequelae, education functions of the hand and foot coordination.

\section{Gynecological diseases}

Sulphurous waters have anti-inflammatory and anti-allergic effect anf on gynaecological diseases are influencing favourable secretory glands of the cervix. Also favors restoring vaginal biological components.

Sulphurous waters are recommended to prop hylactic purpose for genital functional disorders with hyporesponsive background caused by:

- ovarian failure with or without other endocrine disorders;

- local disturbances hormone receptors or primitive or secondary functional disorders such as hypotonic uterus, frigidity, etc.,

- reduction of general and local defense capability against inflammatory agents of the genitals,

- insufficient enzymatic-metabolic;

- lack of menstruation,

- dematoze vulvar, chronic eczema, genital prolapse;

- chronic ulcerative cervical infections attached, painful.
Respiratory diseases

Removing patient suffering of lung disease from polluted environment in which to live and accommodation in an environment free of irritants create favourable environmental conditions applying therapy.

Prophylactically cure addresses workers who work with dust, lint, toxic gases, humidity or dry air, temperature variations, etc. and are prone to allergic bronchopulmonary inflammatory diseases.

Therapeutic cure are recommended for recovering pneumopathies acute bacterial and viral, tracheo-bronchitis chronic simple respiratory neurosis.

Sulphurous mineral waters used as inhaled have an wetting action on the bronchial tract, favoring bronchial secretion drainage products.

Internal cure with sulphurous water is indicated in:

chronic gastritis with hypopeptic and hyposecretion;

enterocolitis and intestinal dyspepsia,

postoperative sequelae on bile ducts;

diabetes mellitus, hyperuricaemia,

sequelae after renal disease, urinary stones

Bibliography

1. Teleki N., Munteanu L. and Bibicioiu S. (2004). Romania Balneara - ghid pentru medicii de familie si pentru medicii specialisti. Bucuresti.

2. Dima A., Cristea A. (2011). Ape sulfuroase in cura balneara pentru patologia artrozica a trenului inferior. Prezentare Conferinta Nationala de Balneologie - editia a $I X-a$.

http://www.farmaciata.ro

http://indianherbal.ro

http://ayurvedaromania.ro 